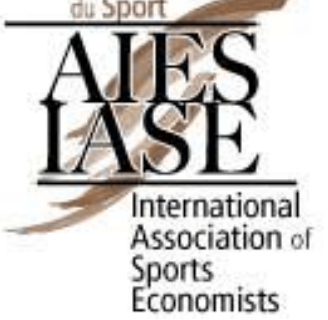

IASE/NAASE Working Paper Series, Paper No. 07-25

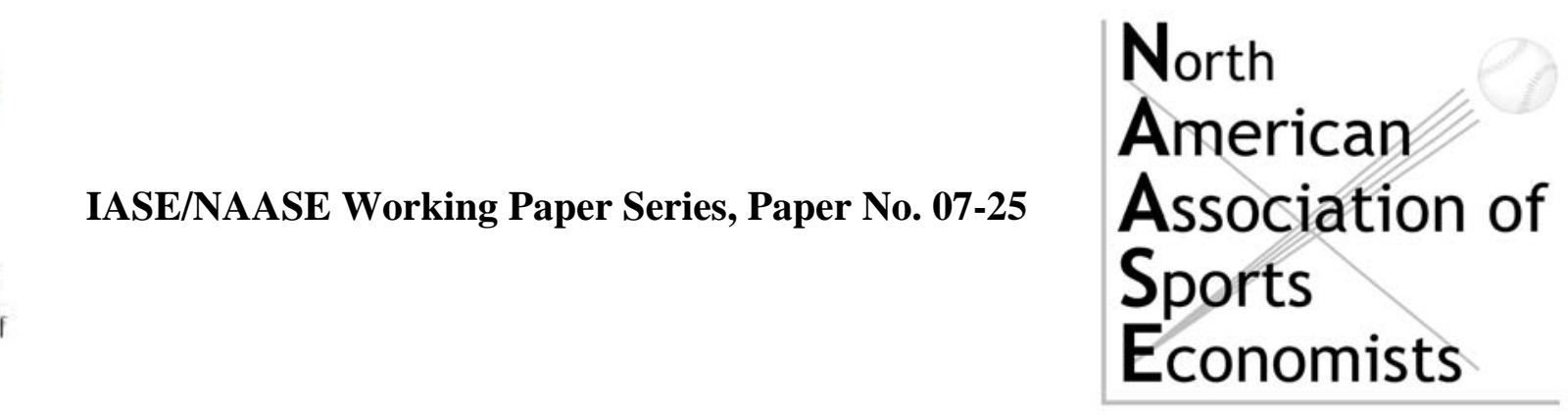

\title{
One year later: A re-appraisal of the economics of the 2006 soccer World Cup
}

\author{
Wolfgang Maennig ${ }^{1}$
}

July 2007

\begin{abstract}
No two ways about it: the soccer World Cup competition in June 2006 in Germany was a great experience, not only for the soccer fans, and it still resonates far and wide. The various commentaries have all concluded that the economic effects were positive. Emphasis has often been placed on increased turnover in the retail trade, overnight accommodation, receipts from tourism and effects on employment. The present study shows that this reasoning is mostly of little value and may even be incorrect. Of more significance, however, are other (measurable) effects such as the novelty effect of the stadiums, the improved image for Germany and the feelgood effect for the population
\end{abstract}

JEL Classification Codes: L83, R53, R58

Keywords: Regional economics, sports economics, World Cup, Stadium Impact

This paper is also available as University of Hamburg Working Paper Series in Economic Policy, Number 10/2007.

${ }^{1}$ University of Hamburg, Chair for Economic Policy, Von-Melle-Park 5, 20146 Hamburg, Germany, E-mail: maennig@econ.uni-hamburg.de, phone: +49 (0)40 42838 - 4622, fax: +49 (0)40 42838 - 6251 


\title{
One year later: A re-appraisal of the economics of the 2006 soccer World Cup
}

\begin{abstract}
No two ways about it: the soccer World Cup competition in June 2006 in Germany was a great experience, not only for the soccer fans, and it still resonates far and wide. The various commentaries have all concluded that the economic effects were positive. Emphasis has often been placed on increased turnover in the retail trade, overnight accommodation, receipts from tourism and effects on employment. The present study shows that this reasoning is mostly of little value and may even be incorrect. Of more significance, however, are other (measurable) effects such as the novelty effect of the stadiums, the improved image for Germany and the feelgood effect for the population
\end{abstract}

Keywords: Regional economics, sports economics, World Cup, Stadium Impact JEL classification: L83, R53, R58

Version: June 2007

The economic success of the World Cup begins with the financial success of the organizing committee, which was able to achieve a surplus of $€ 155$ million; part of this surplus was passed to the German Olympic Sports Association, with the result that sports other than soccer have also benefited financially from the soccer World Cup (N.N. 2007c). In addition there are, for example, reports from television companies that there were considerable increases in viewer ratings for the World Cup (N.N. 2007a), and reports of increased turnover for manufacturers of table-football equipment and for breweries. $^{1}$ Although it cannot be denied that individual enterprises and sectors have profited, the economic effects will be investigated more fully below on the basis of developments in meso- and macro-economic data. These data have the advantage that they

University of Hamburg, Faculty Economics and Social Sciences, Department of Economics and Business Administration. Von-Melle-Park 5, 20146 Hamburg, Germany. E-mail: maennig@econ.unihamburg.de. Phone: +49 (0)40 42838 - 4622. Fax +49 (0)40 42838 - 6251

1 The enumeration of positive reports does not pretend to be complete. For an overview of more positive reports, see Bundesministerium des Innern (2006). The critical assessment of the effects of the World Cup by Brenke and Wagner (2007) came to the author's attention after the manuscript had been written. 
aggregate possible increases in the profits and incomes of individuals with the losses of others, and thereby present an overall economic picture.

\section{Numbers and prices of overnight stays}

The number of overnight stays in Germany in June 2006 was some 1.6 million higher than in the same month of the previous year; in July the increase amounted to 0.6 million. However, for many reasons it is questionable to attribute this to the soccer World Cup. For one thing, the preceding year might turn out to have been particularly weak. For another, there has in any case been a slightly positive growth in the number of overnight stays in Germany over the past ten years; they have risen from 23.9 million (visitors from within Germany or from other countries) in 1997 to 27.6 million in 2006, which corresponds to an annual growth of $1.4 \%$. The broken line in Figure 1 shows the growth in overnight stays in German hotels for 1997-2006 on the basis of the raw data. It is at once obvious that the overnight numbers show seasonal fluctuation, and it is therefore useful to perform the analysis with the help of seasonally adjusted data. With regard to the trend observed for Germany as a whole, the corresponding seasonally adjusted values (Fig. 1 continuous line; X12 method, US Census Bureau) do not show any deviation that can be attributed to the World Cup $^{2}$. Individual reports from the World Cup host cities present an even more sceptical overall picture. For example, the average utilization of available accommodation in June 2006 compared with June 2005 fell in Berlin by $11.1 \%$ and in Munich by $14.3 \%$ (N.N. 2006d), which points to a World Cuprelated crowding-out effect on normal tourism.

Also, it is clear from Figure 2, which focuses on seasonally adjusted data for overnight stays in the years 2004 to 2006, that the increases during June and July 2006 were immediately preceded and followed by lower numbers in the months of May and August. Note: not only was the normal growth of $1.4 \%$ not achieved in May and August, but there were even lower overnight numbers in absolute terms in comparison with previous years. It is conceivable that tourists who would otherwise have sought overnight ac-

2 Regression analyses using a dummy for the WC period in addition to a constant and a trend variable as explanatory variables for the numbers of overnight stays found no significant effects in the months of June and July 2006. This holds for linear as well as for log-linear regressions, and for a total of five different models of the WC dummies. Details are available from the author. 
commodation in Germany during May and/or August transferred their stay to the World Cup months ('time switching'). This, too, can be interpreted as a crowding-out effect.

Figure 1: Overnight stays in Germany since 1997

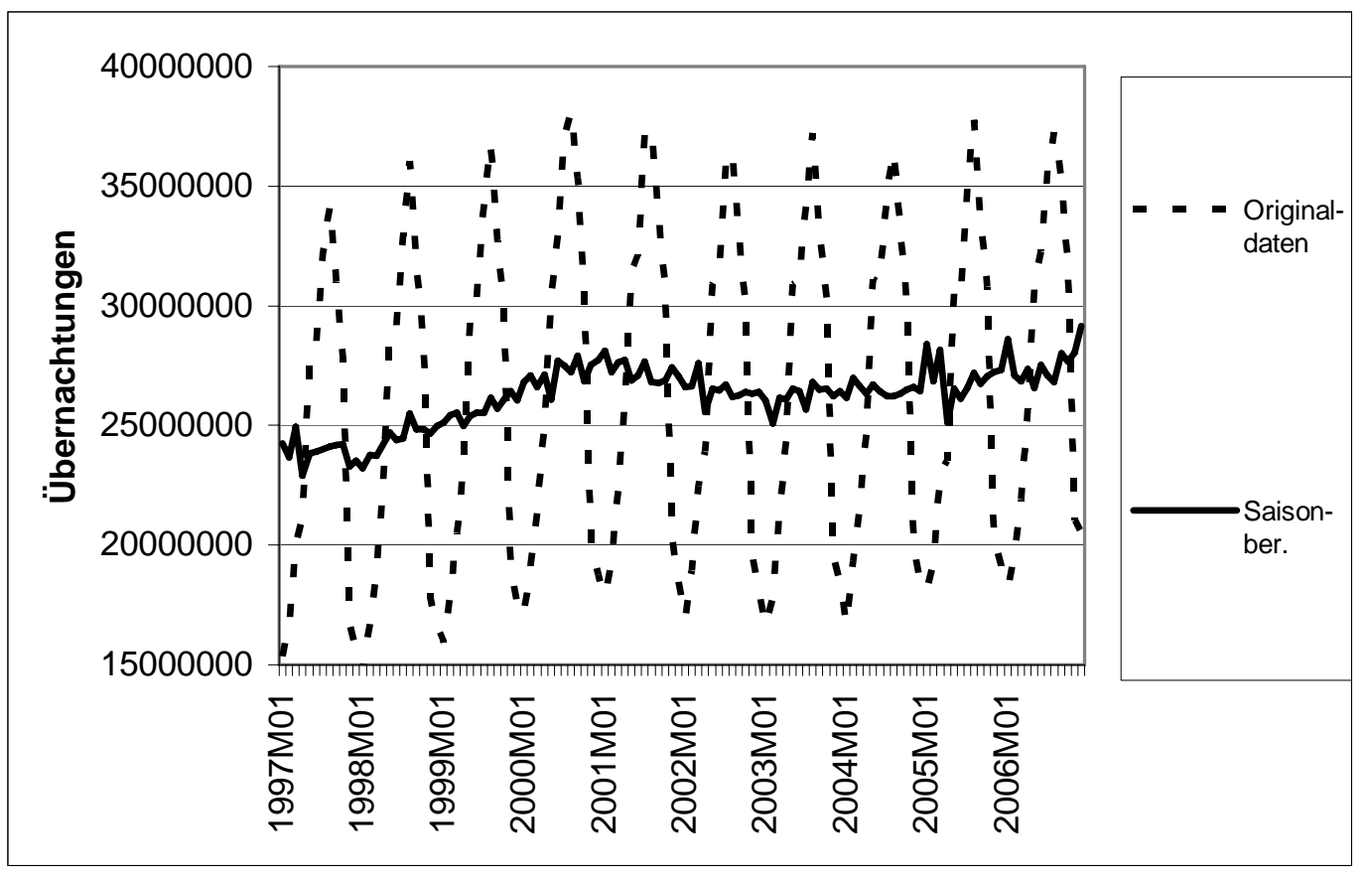

Source: Statistisches Bundesamt: Entwicklung der Ankünfte und Übernachtungen in Beherbergungsstätten, in: Fachserie 6, Reihe 7.1.

However, although the increases in the numbers of overnight stays were not statistically significant, the hotel sector compensated with prices $4.8 \%$ higher than those in June 2005. Even though Figure 3 shows that the price rise remained in place after the World Cup (and therefore could be attributed to other causes such as the general upswing in Germany), this might have contributed to the fact that $41 \%$ of hoteliers nevertheless felt their (positive) expectations of the World Cup to have been realized ${ }^{3}$.

\section{Effects on retail trade}

Some reports have recorded increases in the retail sector of some $€ 2$ milliard based on the World Cup. Figure 4, which represents the percent change in retail sales figures compared with the previous year, reveals that the World Cup months of June and July

${ }^{3}$ (N.N. 2006b). It is interesting, however, that in contrast to this, only $20 \%$ of the restaurant owners claimed to be satisfied, as measured against their expectations. 
2006 were characterized by decreases (!) in turnover. ${ }^{4}$ It must be borne in mind that these numbers do not include possible increases in sales at filling stations and in the field of fan celebrations (which, however, were partly cancelled out by catering losses in other regions): just as already observed for other sporting mega-events, many consumers might have been diverted from their normal consumption behaviour by the World Cup itself, or by what they saw in the stadiums, in the 'Fan-Mile' street markets or on television. Or they chose - and this is an exaggeration - to entertain themselves very well at home by watching the live broadcasts of the soccer and restricting themselves to the consumption of fast food (the 'couch potato' effect).

Figure 2: Seasonally adjusted numbers of overnight stays in the years 2004 to 2006

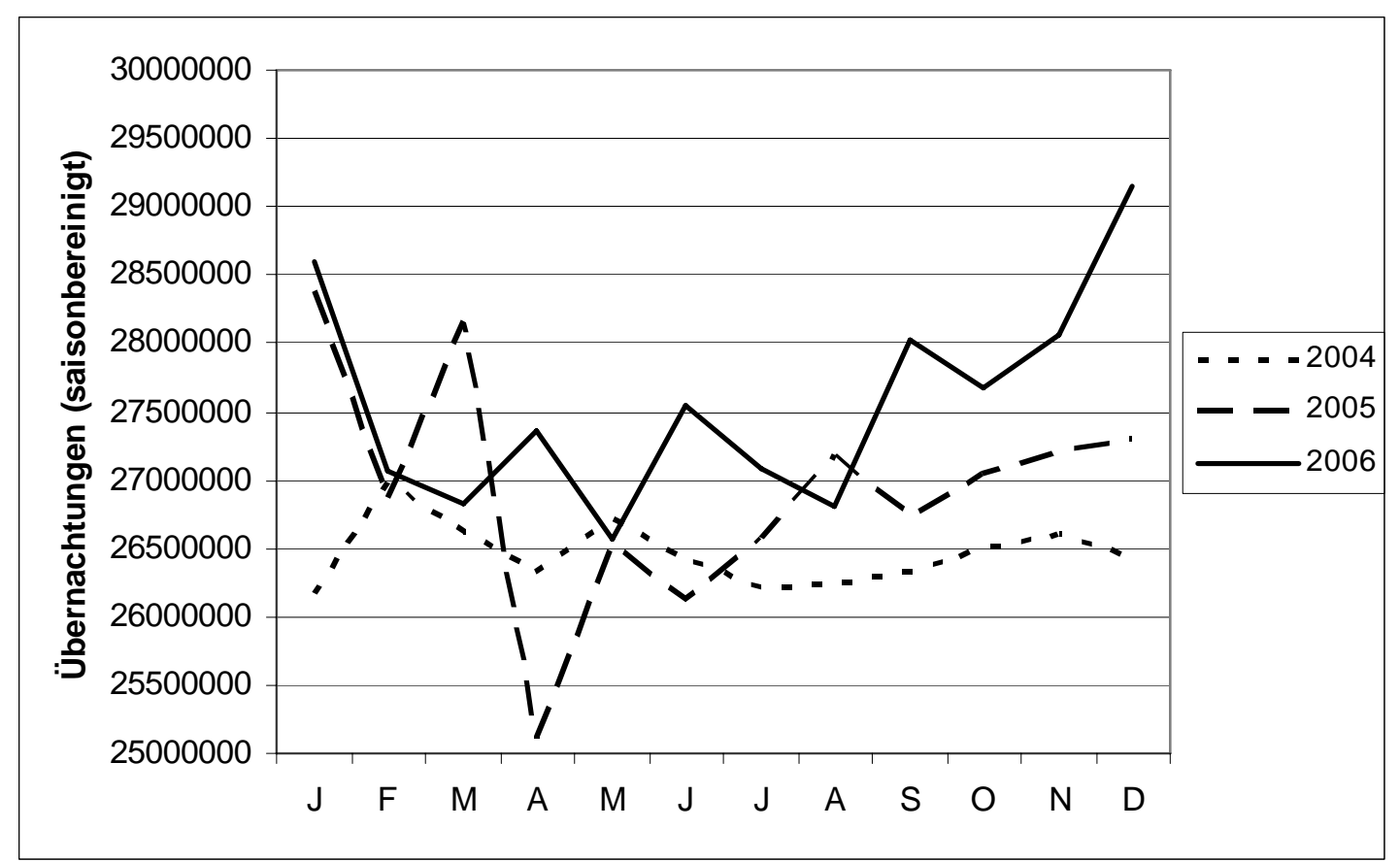

Source: Statistisches Bundesamt: Entwicklung der Ankünfte und Übernachtungen in Beherbergungsstätten, in: Fachserie 6, Reihe 7.1.

\section{Income from international tourism}

The previously reported data regarding consumption and accommodation do not differentiate between the activities of German residents and those of people from other coun-

\footnotetext{
${ }^{4}$ Regression analyses to investigate the retail turnover according to the above-mentioned sample for the period 1/1997 to 11/2006 showed in the months of June and July 2006 no significant effects of the World Cup.
} 
tries. However, analyses of sports events should evaluate the expenditure exclusively of non-residents as an impulse to the economy of the host region. As for the people from within Germany itself, it can be assumed that their increased expenditure during the sporting event is counterbalanced by reductions in their consumption elsewhere and that the savings rate overall remains constant at least in the medium term (Maennig 1998).

It is worth taking a look at the statistics of the service balance sheet, in which the expenditure of foreign tourists is included. The Deutsche Bundesbank reports additional incomes from tourism at $€ 1.5$ milliard in the months from May to July 2006 in comparison with the previous year, in which are included the expenditure for accommodation and travel within Germany as well as the consumption of the World Cup visitors who came from other countries. ${ }^{5}$ Figure 5 shows the clear rise in takings from international tourism, in which a considerable proportion of the additional income had already occurred in May, i.e. well before the start of the World Cup.

5 The Bundesbank detects certain inaccuracies, since, for example, the additional income of local airlines is not included. On the other hand, ticket sales are included, of which a considerable proportion goes to FIFA (Deutsche Bundesbank 2006). 
Figure 3: Price monitor of the German national bureau of statistics: bed and breakfast (deviation of the price index in June 2006 in \%)

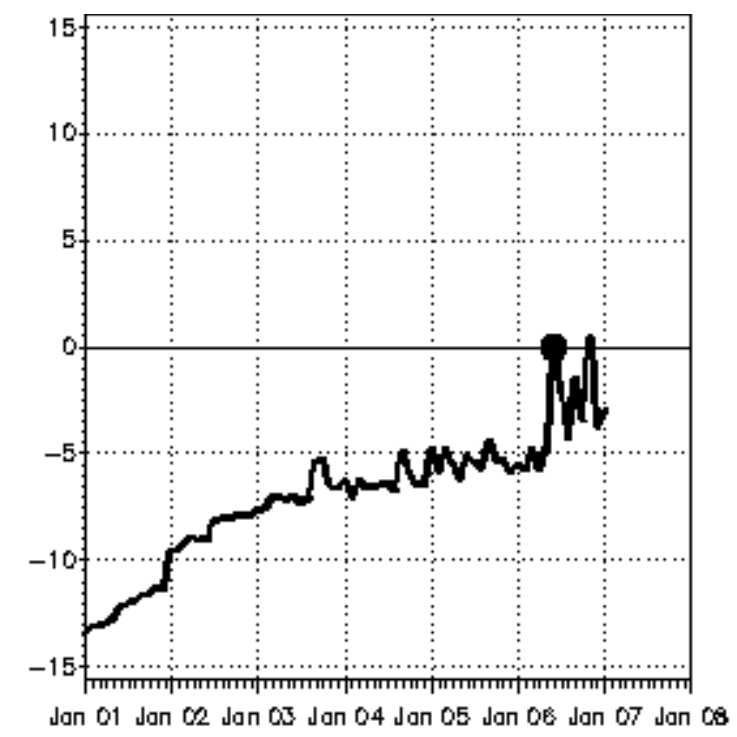

Source: Statistisches Bundesamt: Preismonitor des Statistischen Bundesamtes. Gastronomie. Übernachtung mit Frühstück. Downloaded from http://www.destatis.de/indicators/d/ vpigraf07.htm on 8 March 2007.

The above-mentioned $€ 1.5$ milliard increase in receipts at first appears to be considerable, but must once again be put into perspective in several ways. First, this sum in the order of milliards corresponds to only $0.07 \%$ (!) of the gross domestic product for Germany in 2006. Although this is not of itself an argument against the economic effectiveness of the soccer World Cup, it does emphasize that in a large national economy any impulses are rapidly condemned to statistical insignificance. Hence, it must be emphasized once more that the above-mentioned rise (corresponding to some $22.5 \%$ compared with the same period in the previous year) should be considered against the background of the gradual positive trend that is occurring in any case in receipts from international tourism. Between 1997 and 2005, i.e. disregarding any World Cup effect, the average growth in receipts from international tourism amounted in any case to $\sim 5.1 \%$ per year. In addition one must ask, as already discussed, whether at the same time there were counterbalancing effects of the World Cup, so that the net effect for the balance sheet for tourism turns out to be less positive. Figure 6 demonstrates that expenditure by German tourists in other countries during May to July 2006 was clearly above the level for the previous year. For example, during the World Cup, Mallorca was booked out 
(which is unusual for this time of year) and operated as 'the 13th fanpark' (N.N. 2006a). This 'carnival effect' of large sporting events or the incentive for the local people to 'flee' from the noise, traffic jams, etc., in the host region (and to become consumers in other countries) at least partially cancels out the extra foreign visitors. Although in the case of those tourists in Mallorca who visited the 13th fanpark, the motives may have lain not so much in the avoidance of the sporting event but rather in an enjoyment of the World Cup free of work pressures; even so, the passive net effect of the additional trips abroad of German citizens on the tourism balance sheet still stands, so long as this travel activity is not a question simply of trips that have been either brought forward or delayed.

Figure 4: 'Couch potato effect': retail turnover in Germany, change from the previous year in \%, 2005 and 2006

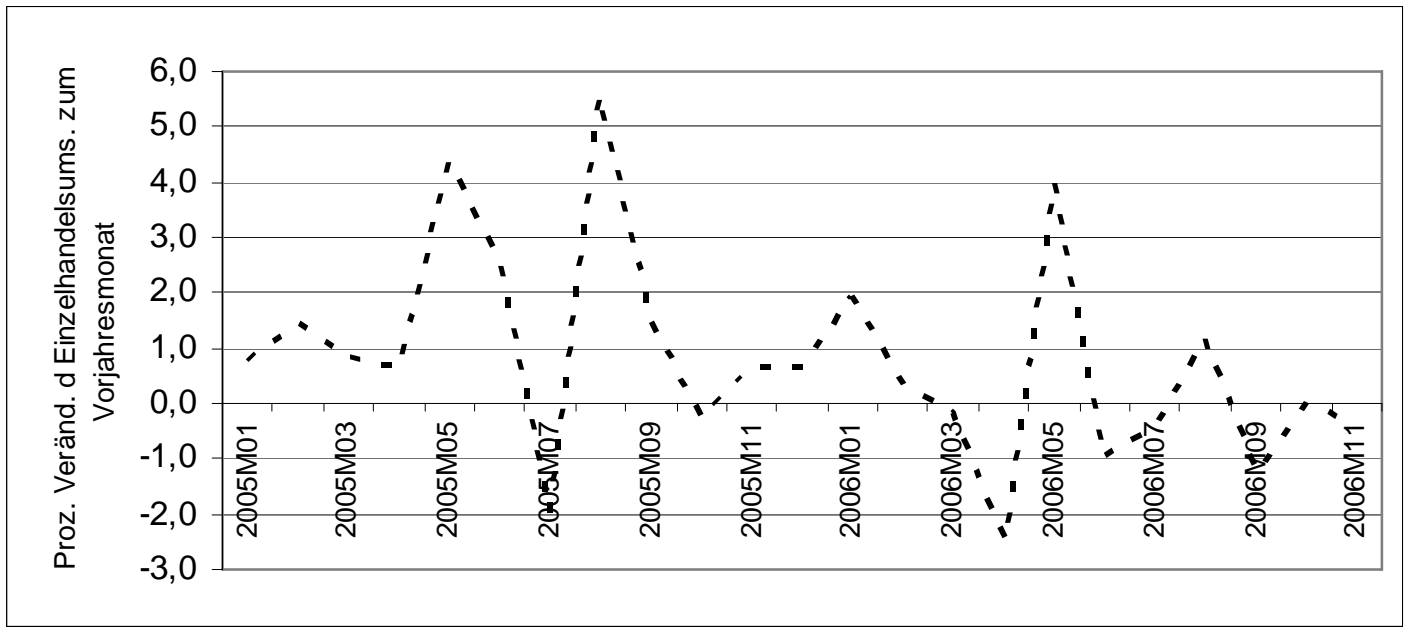

Source: Statistisches Bundesamt. Long-term series: domestic trade, catering and hotel industry, tourism. Real retail sales excluding cars and filling stations. Percent change compared with the same month in the previous year. 
Figure 5: Tourism receipts in Germany, seasonally adjusted

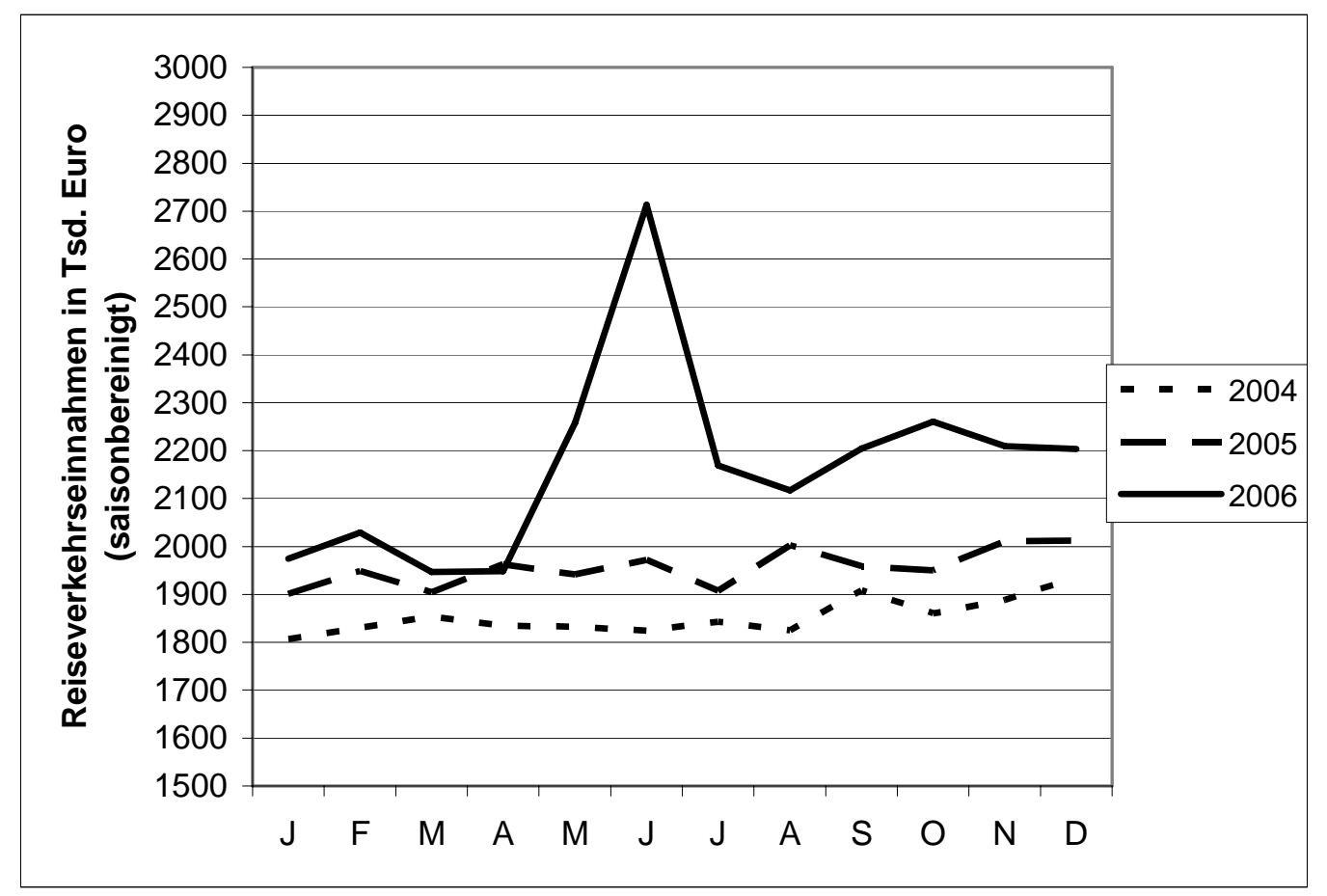

Source: Deutsche Bundesbank: Zeitreihen-Datenbank: Dienstleistungsverkehr mit dem Ausland. Downloaded from

<http://www.bundesbank.de/statistik/statistik_zeitreihen.php?func=list\&tr=www_s201_b02> on 8 March 2007.

A comprehensive comparison of the tourism balance sheets for the months of May to July 2006 gives a decrease of $\sim € 324$ million in the (traditionally passive) German tourism service balance (seasonally adjusted: $€ 309$ million, corresponding to $0.01 \%$ of the GDP). Over the whole of the year 2006, there was overall a net improvement of only $€ 60$ million in comparison with 2005 - an amount that in terms of the total economy is negligible, from whatever perspective it is considered.

\section{Employment effect}

The national labour agency reports 25,000 to 50,000 additional jobs arising from the World Cup, although most of them were temporary in nature (N.N. 2006c). From the point of view of just 40 million persons gainfully employed in Germany this corresponds to an increase of $0.06 \%$ to $0.13 \%$. Here, too, it is appropriate that whatever increases in employment there may have been at the time of the World Cup be adjusted in the context of an employment trend that overall in the year 2006 was distinctly positive. Throughout 2006 the employment figures exceeded the values for the corresponding 
months in the previous year. However - and this is true not only for the raw data but also for the seasonally adjusted data - the otherwise usual seasonal downturn in the employment figures for June and July did not occur in 2006. Nevertheless, statistical evidence of economically significant increases in employment through the World Cup is hard to find. ${ }^{6}$ It must again be borne in mind that in the larger economies any impulse is rapidly consigned to insignificance.

All together, it must be taken as an interim result that most of the effects on turnovers of retail business, tourism and employment that feature in the foreground of discussions about the economics of the soccer World Cup (and other major sporting events) turn out, at least in the short term, to be smaller than supposed. It is not at present possible to determine whether there will be positive medium- or long-term effects of the 2006 World Cup on the host cities; however, on the grounds of empirical studies of comparable sporting events it appears at least that they cannot be guaranteed. ${ }^{7}$

6 Regressions performed on the above-mentioned sample yielded no significant values for the World Cup dummies. Hagn and Maennig (2007b) in a multivariate study do not find any significant decreases in unemployment in the host cities of the 2006 soccer World Cup.

7 For the 1974 soccer World Cup, no significant short-, medium- or long-term effects on employment in the German host cities can be seen (Hagn and Maennig 2007a). For the 1996 Olympic Games in Atlanta there are significant positive medium-term effects on employment, but no significant effects on wages (Hotchkiss, Moore and Zobey 2003). With regard to the 1972 Olympic Games in Munich, there are significant positive long-term effects on incomes in areas of Germany in which contests of the Games took place, but no significant effect on employment (Jasmand and Maennig 2007). For an overview of empirical studies of short-term effects and/or other sports events, see du Plessis and Maennig (2007). 
Figure 6: German tourism expenditure for the years 2004 to 2006, seasonally adjusted

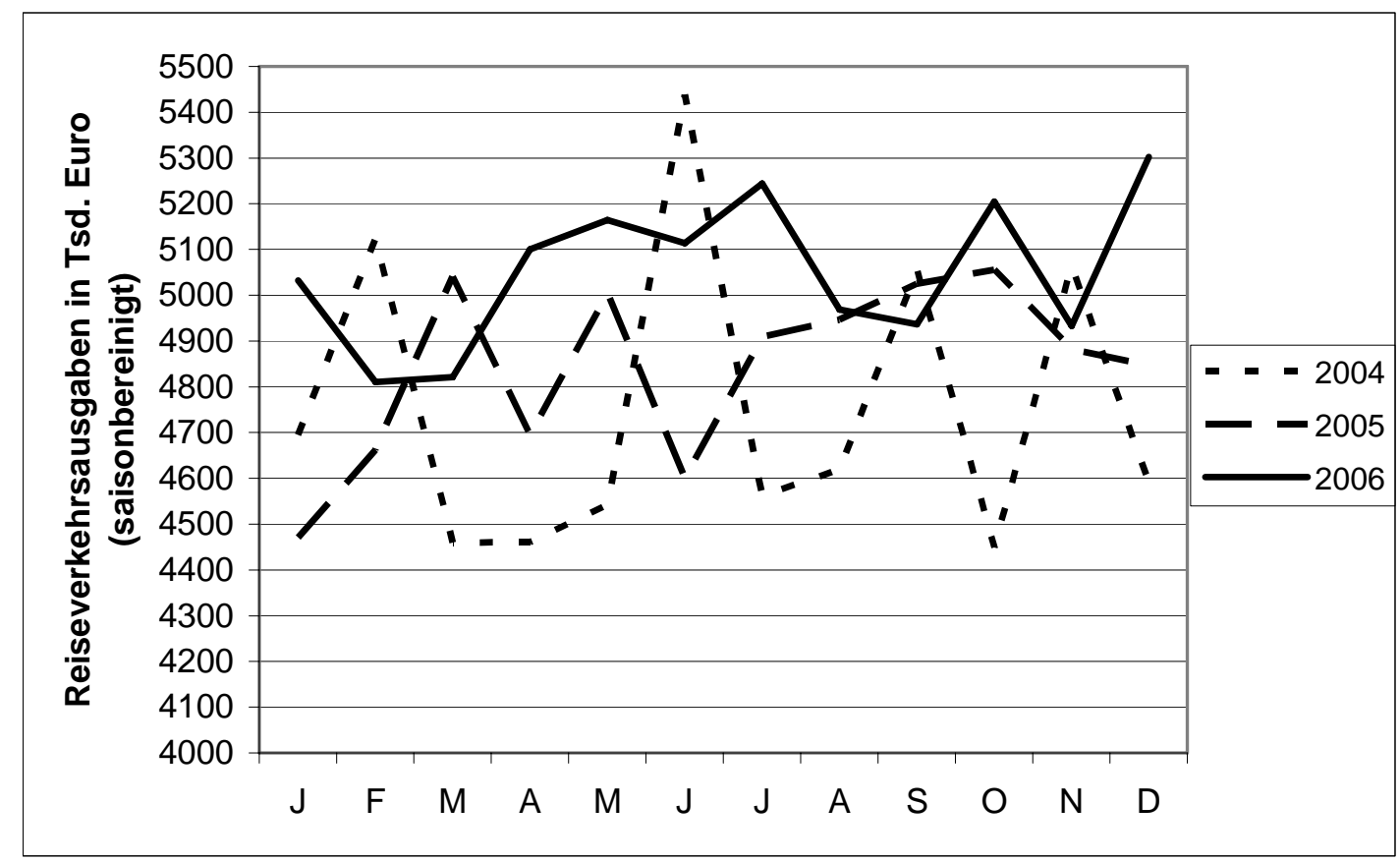

Source: Deutsche Bundesbank loc. cit.

\section{World Cup stadiums, novelty effect and urban development}

Following on from this first disappointing interim balance sheet, consideration should be given to the likelihood of positive effects in other areas that are frequently given less attention in descriptions of the 2006 World Cup, for example because they are presumed to be negative or less satisfactorily quantifiable.

It is worth beginning with construction works. The expenditure on the stadiums in which the World Cup was held reached more than €1.4 milliard (Feddersen et al., 2006). In addition, investments in the related infrastructure amounted to nearly €2 milliard (Maennig and Buettner, 2007).

First, it should be stressed that this expenditure should not be equated with the corresponding World Cup costs. This is obvious, for example, for the 'World Cup' stadiums in Hamburg and Gelsenkirchen, which were already in place before FIFA had finalized the decision in 2000 to award the World Cup competition to Germany. But even with the stadiums that were built or modernized after the announcement, the costs can not all be attributed to the World Cup. A particularly illuminating example is the arena in $\mathrm{Mu}$ nich: 'FC Bayern' and to some extent '1860' have used the Munich Olympic stadium 
since 1972, but have long wished for a stadium offering greater comfort and atmosphere, in particular better accommodation for VIPs and business contacts. However, the architect's copyright, the needs of monument protection, and the wish to preserve the athletics track all contributed to the impossibility of undertaking improvements to the Olympic stadium.

Although the two clubs were ready to bear the cost of the new building themselves, public support was initially weak on account of concerns over a future largely unused (and perhaps deteriorating) Olympic stadium (a 'Coliseum' effect). Only after Franz Beckenbauer, President of the Organizing Committee for the 2006 World Cup and Vice-President of FC Bayern, warned that Munich would be considerably disadvantaged in the process of selection of the World Cup host cities, did a survey of the public in Munich open the way for a new building in Munich-Fröttmaning. The World Cup was therefore in no way the cause of the investment, but was a welcome inducement. A similar reasoning is valid for all 12 of the 'World Cup' stadiums, perhaps with the exception of Leipzig.

Costs (of stadiums) should be seen as the portion of use of resources that arises through the production of a given product in a specified period (here, the World Cup in June/July 2006). The World Cup and other events generate costs because they (can) contribute to the wear and tear of the stadium, which is normally written off as depreciation. With regard to the amount of these costs, it can be noted, for example, that stadiums erected or modernized in connection with the 1974 soccer World Cup after about 30 years no longer met the economic requirements of the soccer clubs. On the assumption of linear depreciation, these costs take the form of a depreciation amounting to $\sim 3.3 \%$ of the size of the investment per year. This corresponds to $0.6 \%$ or $€ 9$ million of World Cup-derived stadium costs on the basis of 10 weeks exclusive use of the stadium for the World Cup, including the periods of pre- and post-match operations. The organizing committee assigned $€ 1.5$ million to each stadium operator (DFB 2007), so that these costs would be fully covered out of the 2006 World Cup budget. ${ }^{8}$ A similar rea-

8 Each city received $€ 300,000$ from the budget of the organizing committee, which, however, could not cover the city's costs for insurance, decorations, places for warming up, etc. 
soning held also for the above-mentioned infrastructure, provided it was built in such a way as to make a positive contribution to the future use of the stadium.

If the stadium constructions and their expenditure should not be charged to the World Cup, then this of course is true also for the resultant long-term uses of the stadium. At the outset, it should be pointed out - particularly for those who apportion the stadium investments to the World Cup in an incorrect manner - that new stadium structures or stadium modernizations consistently engender novelty value: curiosity and improved comfort entice additional visitors to the stadium. In Germany, multivariate studies on all stadium projects since 1963 have demonstrated that a rise in spectator numbers of $\sim 2700$, or $\sim 10 \%$ per match, is attributable to the influence of the new stadium rather than to that of other factors that may influence spectator demand (Feddersen et al., 2006). In selected soccer stadiums, the novelty effect can even turn out to be markedly greater; Hamburg and Gelsenkirchen can be cited as examples of this, with the growth in spectators after the opening of the new buildings (shown by the vertical lines in Figures $7 \mathrm{a}$ and $7 \mathrm{~b}$ ) clearly rising more strongly. To this, add the fact that the average revenue per ticket rises because of the expanded area of VIP and business seating, so the overall ticket proceeds can rise. These increased receipts improve the ability of a club to acquire top players in the international market, and this leads in the medium term to an increased national and international competitive ability. Hence, from the point of view of sport, the new stadiums are an obvious asset for Germany.

On the other hand, in Germany the opportunity was missed to aim not only for an optimization of the management efficiency of the professional clubs, but also for a particularly attractive, spectacular, 'iconic' architecture of the stadium to create an urban impulse in each city, with which the process of development of each region could have been accelerated (Maennig 2006). The architecture of the German 'World Cup’ stadiums overall can be described as 'functional', while freely conceding that many technical innovations and creative architectural ideas are bound up in the stadiums. It must also be recognized that the beauty and attractiveness (also) of stadiums lies always in the eyes of the (loving) beholders. 
Figure 7: Novelty effect in the stadiums of Hamburg and Gelsenkirchen; Average number of spectators per match

\section{a) Hamburg}

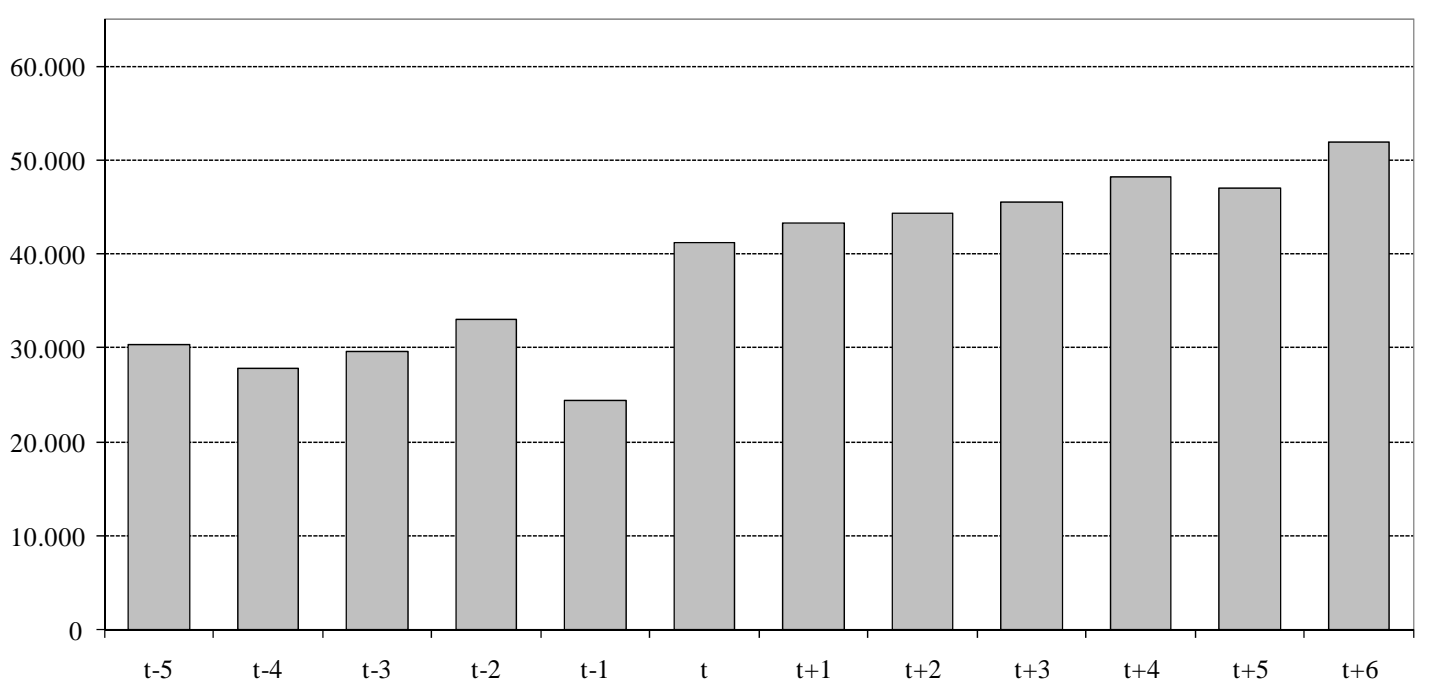

\section{b) Gelsenkirchen}

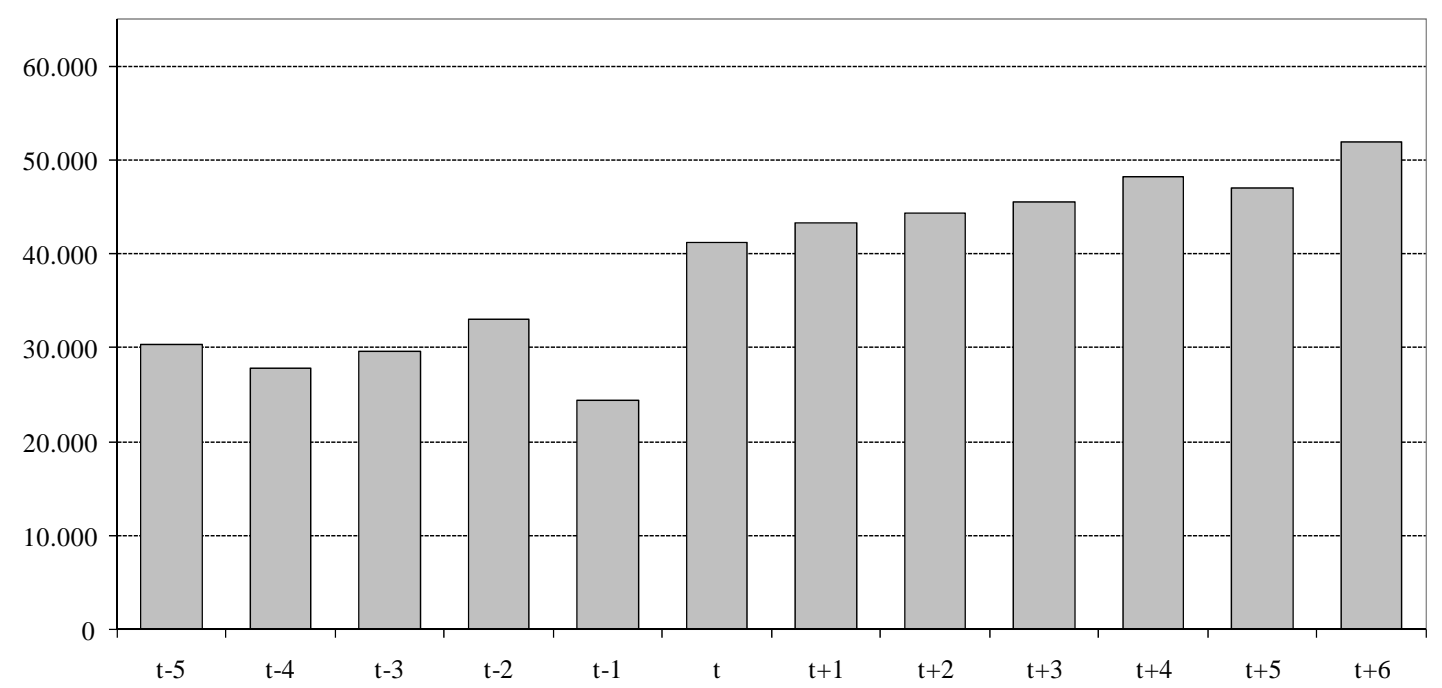

Source: Maennig, W., A. Feddersen, M. Borcherding: Zum Neuigkeitseffekt von Stadionneubauten. Gutachten im Auftrag des Bundesinstituts für Sportwissenschaft, Hamburg, 2004. 
Nevertheless, there are no unique new constructions and iconic architectural features with trans-regional significance - except for the Munich arena. This, however, had to be situated too far from the city centre to generate a positive effect for Munich in the foreseeable future. ${ }^{9}$

There is no standard definition of 'iconic buildings ${ }^{\text {, }}{ }^{10}$, but there are plenty of examples among the structures that have been built: the Sydney Opera House is inseparable from the worldwide image of that city, and the Guggenheim Museum in Bilbao, which has given its name to the 'Bilbao effect' that is so lacking in the German stadiums, has converted that Spanish city, which hitherto went largely unnoticed on the international scene, into one of the five most visited cities of Spain. There are even examples within sports architecture: the Munich Olympic Stadium with its architecture has become one of the best-known symbols of Munich and is still drawing visitors to the city.

Meanwhile the effect of 'iconic' architecture is valued worldwide, and in many cities it is one of the most important parts of that city's development strategy. In Germany on the other hand, the subject is still little considered, including for other areas than sports complexes. Admittedly, Hamburg has now chosen, with its projected Elbe Philharmonic Hall, what is acknowledged to be a striking architectural design, in order to redress the perceived shortcoming that, although the name of the city is familiar worldwide, people generally have no mental pictures of the city. And Frankfurt has meanwhile established an explicit requirement for 'spectacular projects’ (N.N. 2007d). There are, incidentally, also plenty of international examples of iconic stadium projects. ${ }^{11}$

The club managers should not be blamed; they have the task of maximizing the income for their teams. For this, they must confine their endeavours to whatever is necessary to keep the fans happy. It is not their business to participate in municipal or regional politics, to make their architecture interesting from the point of view of the cityscape and to achieve 'external' effects for the regional economy, from which their budgets do not

9 For the role of the (central) location of stadiums on city development, see particularly Nelson (2001, 2002) and Santo (2005).

10 For a list of characteristic properties of this type of building, see Maennig (2006).

11 For the South African preparations for the 2010 soccer World Cup, particularly in Durban, see Maennig and Schwarthoff (2006). 
profit. Responsibility would have rested with the local authorities and their policy makers, who would have had to bear the additional costs of ambitious architecture (and, where applicable, the better location). Nota bene: the Munich Arena cost about €280 million, whereas the average for the rest of the World Cup stadiums was about $€ 100$ million. Considering the restricted public funds and the attitude increasingly encountered in the population that one should not give more public financial support to soccer 'millionaires', this would hardly have pleased the politicians. So the German World Cup stadiums were about 75\% privately financed, if one excludes the two historicalpolitical stadiums in Berlin and Leipzig - and were accordingly reduced to 'soccer functionalities'. To that extent, the voters themselves bear the responsibility for the missed opportunity to boost a city's development.

\section{International perception of Germany and the feelgood effect for Ger- man residents}

As a result of the World Cup, the perception of Germany has risen in other countries. The erstwhile image abroad of Germany as 'hard and cold ... not a nation much associated with warmth, hospitality, beauty, culture or fun, ${ }^{12}$ was improved through the World Cup in all 17 criteria that constitute the 'Anholt Nation Brand Index'. The greatest increase in approval was scored by the statement or question 'This country excels in sport'. Figure 8 shows the trend in selected questions that were presented with a scale of 6 (very good, complete agreement) to 1 (poor, no agreement).

An additional significant effect of the World Cup must have been the experience for the German citizens, who might have been strongly influenced by the 'public viewing' in the fan-parks. Quantitative ex ante and ex post studies of sports events have up to now mostly ignored the value of an improved perception as well as the feelgood effects experienced by the people in the economy when the event takes place in their neighbourhood, even if they themselves do not visit the stadium. Even though this effect can have great significance, only a few studies ${ }^{13}$ attempt, through a survey of payment reserves

\footnotetext{
12 Anholt Nation Brand Index: Q3 Report, Seattle et al., 2006.

13 Johnson and Whitehead (2000), however, study the willingness of people to pay for two stadium projects in Lexington, Kentucky, even if they do not visit the stadiums. Atkinson et al (2006) evaluate the British WTP for the Olympic Games in London 2012.
} 
(willingness to pay), to evaluate this phenomenon of benefiting from (sports) events without active attendance at the stadium - a concept usually somewhat misleadingly termed in the sports economics literature the 'non-use effect'. Before the World Cup, only one out of five Germans had a 'willingness to pay' (WTP) for the World Cup to take place in Germany that differed from zero (Heyne et al., 2007). On average, the WTP was $€ 4.26$ per person, which with 82 million inhabitants corresponds to $€ 351.5$ million. After the World Cup 42.6\% had a positive WTP, and the average was €10.0, amounting to $€ 830.8$ million for the whole country. Since only a few of the 82 million Germans themselves had tickets to attend a stadium for a World Cup match, the willingness to pay can be interpreted as a 'non-use effect'. These effects are often called 'intangibles', yet they are perfectly quantifiable and they were among the largest effects of the World Cup. ${ }^{14}$

\section{Figure 8: International perception of Germany}

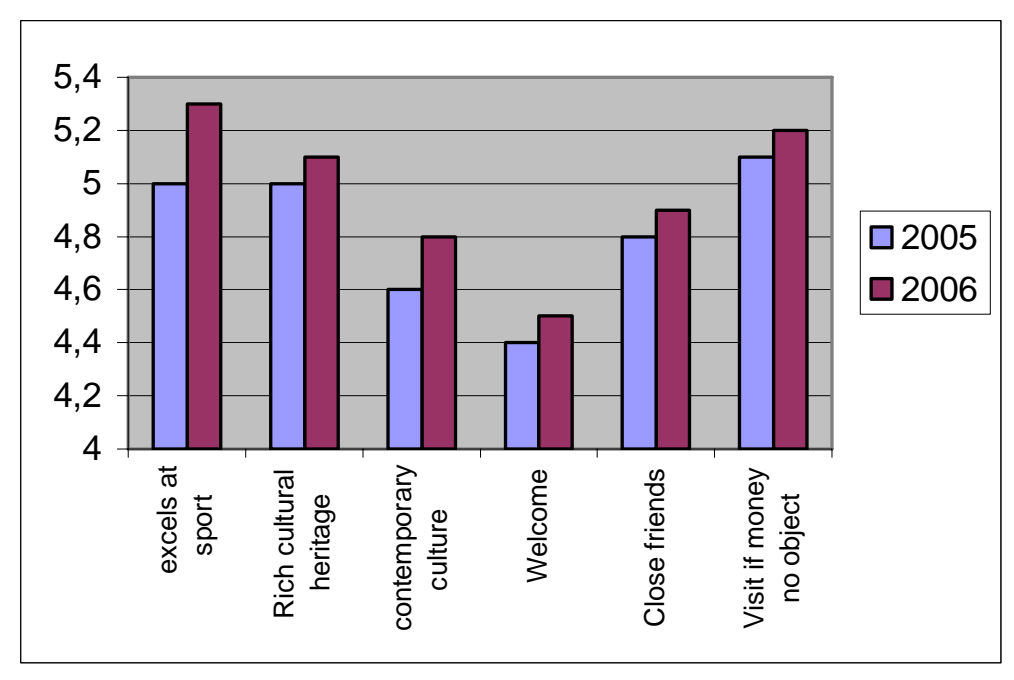

Source: Wave 3/2005 and 3/2006 GMI-Anholt Nations Brand Index

14 Heyne et al. (2007) report that the increase in the willingness to pay is attributable above all to a change of attitude in those who, before the World Cup, were not willing to pay anything. After the World Cup, an increased willingness to pay was expressed particularly among East Germans, but also among low-skilled persons. Heyne et al. conclude that major sporting events have a characteristic 'experience value'; consumers cannot correctly estimate the quality of an event before their first experience of it, and hence cannot predict their willingness to pay for it. 


\section{Summary}

The long-term economic effects of the soccer World Cup, such as from the improved image, can not yet be evaluated after only one year. In certain areas - the development strategies of the cities were singled out - there have at any rate been opportunities for optimization, with which the long-term benefits would have been increased. But wisdom comes with hindsight, and the responsibility does not lie with the organizers of the World Cup.

The preceding analysis, restricted to the short-term effects, has shown that the impulses in retail business, tourism and employment, which are frequently in the forefront of any proposals for major sporting events, may indeed have been partly positive; however, they were not sufficient to have had any overall economic significance. For some sectors such as the retail trade there may even have been negative developments - contrary to the official perceptions of this sector.

For many people this is a disappointing outcome in terms of the 'pecuniary' effects, but it must be added that the economic costs of the 2006 World Cup, too, were low enough to be disregarded; only a negligible proportion of the costs of stadium construction and infrastructure should be apportioned to the soccer World Cup.

The greatest effect of the 2006 World Cup occurred in aspects that for a long time have not received much attention in economic analyses, because they were mistakenly regarded either as not quantifiable and/or even as non-economic effects. The willingness to pay of the German public for the 'non-use effects' such as the feelgood effects and the improved international perception of Germany, however, amounted almost to the order of milliards; hence these effects are the greatest measurable effects of the 2006 World Cup. Greater willingness to pay for a sporting event or for other events in Germany has, as far as the author knows, not hitherto been recorded. In this respect, it is established that from an economic point of view the 2006 soccer World Cup was one of the greatest and economically most important events in Germany.

To end on a positive note, mention must be made of a reported increase in the birth rate nine months after the soccer World Cup - anecdotal, although not yet statistically confirmed. The World Cup is seen as the cause, because many people in Germany were led by the relaxed, happy atmosphere of the World Cup to forget their cares and stresses ... 
(N.N. 2007b). In view of the low birth rate in Germany, this could be not only one of the finest, but also one of the economically most long-term effects of the 2006 World Cup.

\section{Literature}

Atkinson, G., S. Mourato and S. Szymanski (2006), Quantifying the "un-quantifiable”: Valuing the intangible Impacts of Hosting the Summer Olympic Games. London, unpublished manuscript, London School of Economics and Imperial College London.

Bundesministerium des Innern (2006), Die Welt war zu Gast bei Freunden. Bilanz der Bundesregierung zur FIFA Fußball-Weltmeisterschaft 2006, Berlin.

Brenke, K., G.G. Wagner (2007), Zum volkswirtschaftlichen Wert der FussballWeltmeisterschaft 2006 in Deutschland. DIW Berlin Research Notes 19.

Deutsche Bundesbank (2006), Der WM-Effekt bei den Reiseverkehrseinnahmen in Deutschland, Monthly report, November 2006, 43.

DFB: FIFA WM 2006 auch wirtschaftlich ein großer Erfolg. Report from September 14th, 2006, http://www.dfb.de/index.php?id=500014\&no_cache=1\&tx_dfbnews _pi1[showUid] $=4838 \&$ tx_dfbnews_pi1[sword]=WM\%20wirtschaftlich\%20Erfolg\& cHash=b7c15a208a, retrieved am 3.4.2007.

du Plessis, St., W. Maennig (2007), World Cup 2010, South African economic perspectives and policy challenges informed by the experience of Germany 2006, Working paper Stellenbosch University and Hamburg University 2007.

Feddersen, A., W. Maennig, M. Borcherding (2006), New Stadia for the World Cup 2006 in Germany: Is the Novelty Effect Big Enough?, in: International Journal of Sport Finance, 1 (3), 174-188.

Hagn, F., W. Maennig (2007), Labour market effects of the Football World Cup 2006 in Germany. Working Paper, Hamburg University

M. Heyne, W. Maennig and B. Süssmuth (2007), Mega-sporting events as experience goods? Working Paper Bremen University, University of Technologie Munich and Hamburg University 2007.

Hotchkiss, J., R. E. Moore and S. M. Zobey (2003), Impact of the 1996 Summer Olympic Games on Employment and Wages in Georgia, in: Southern Economic Journal, 69, 691-704.

Jasmand, St., W. Maennig (2007), Regional Income and Employment Effects of the 1972 Munich Olympic Summer Games, Working Paper Hamburg University.

Johnson, B.K., J.C. Whitehead (2000), Value of public goods from sports stadiums: The CVM approach, Contemporary Economic Policy, 18 (1), 48-58.

Maennig, W. (1998), Möglichkeiten und Grenzen von Kosten-Nutzen-Analysen im Sport (Scope and limits of cost-benefit analysis in sport), in: Sportwissenschaft 28 (3), 311-327. 
Maennig, W. (2006), Ikonen statt Schüsseln, in: Immobilienmanager, 7-8, 32-34.

Maennig, W., N. Buettner: Infrastrukturinvestitionen bei Sportstadienneu-, -um- und ausbauten: Der Fall der Fußball-WM 2006, in: E. Theoni, M.-P. Büch, E. Kornexel (Hrsg.): Effektivität und Effizienz öffentlicher Sportförderung, Schorndorf 2007, 107-138

Maennig, W. , F. Schwarthoff (2006), Stadium architecture and regional economic development: International experience and the plans of Durban, South Africa, in: D. Torres (ed.), Major Sport Events as Opportunity for Development. Valencia, 120129.

Nelson, A.C.: (2001), Prosperity or blight? A question of Major League Stadia Location, in: Economic Development Quarterly, 15, 255-265

Nelson, A.C. (2002), Locating Major league stadiums where they can make a difference: Empirical analysis with implications for all major public venues, in: Public works management policy, 7, 98-114.

N.N. (2006a), Der dreizehnte WM-Standort, in: Frankfurter Allgemeine, June 12th, 2006, 13.

N.N. (2006b), Tourismus profitiert nachhaltig, in: Frankfurter Allgemeine, July 1st, 2006, 48.

N.N. (2006c), Für mindestens 25.000 neue Jobs, in: Frankfurter Allgemeine July 10th, 40.

N.N. (2006d), Hotels mit positiver Zwischenbilanz, in: Frankfurter Allgemeine, August 3rd, 2006, 10.

N.N (2007a) “Television broadcasts wider, longer and farther than ever before”, sport intern, E-MAIL SPECIAL, February $16^{\text {th }}, 2007$.

N.N. (2007b), Sport stimulates Germany’s beds”, in: sport intern, E-MAIL SPECIAL, February $16^{\text {th }}, 2007$.

N.N. (2007c). WM 2006 finanziell ein noch größerer Gewinn, in: Frankfurter Allgemeine, March 3rd, 2007, 17.

N.N. (2007d), Frankfurt braucht spektakuläre Projekte“, in: Frankfurter Allgemeine. March 30th., 2007, 49.

Santo, C. (2005), The economic impact of sports stadiums: Recasting the analysis in context, in: Journal of Urban Affairs, 27 (2), 177-192 